\title{
Efficient Agrobacterium-mediated Transformation and the Usefulness of a Synthetic GFP Reporter Gene in Leading Varieties of Japonica Rice
}

\author{
Fujio HASHIZUME ${ }^{1}$, Tohru TSUCHIYA ${ }^{2}$, Masashi UGAKI ${ }^{3}$, Yasuo NIWA ${ }^{4}$, Naoki TACHIBANA ${ }^{1}$ \\ and Yasuo KOWYAMA*2 \\ ${ }^{1}$ Mie Prefectural Science and Technology Promotion Center, Agricultural Research Center, Ureshino, \\ Mie 515-2316, Japan. \\ ${ }^{2}$ Faculty of Bioresources, Mie University, Tsu, Mie 514-8507, Japan. \\ ${ }^{3}$ National Institute of Agrobiological Resources, Tsukuba, Ibaraki 305-8602, Japan. \\ ${ }^{4}$ School of Food and Nutritional Sciences, University of Shizuoka, Yada, Shizuoka 422-8526, Japan. \\ *Corresponding Author E-mail:
}

Received 3 February 1999; accepted 27 July 1999

\begin{abstract}
We have established an efficient Agrobacterium-mediated transformation method in some leading varieties of Japonica rice (Oryza sativa, L.), including Koshihikari. Scutellum calli were induced from mature seeds on our revised medium, KA1, with high frequencies (50 to 70\%) and were used for coculture with Agrobacterium tumefaciens EHA101 which carries binary vector harboring either $\beta$ glucuronidase $(G U S)$ gene or synthetic green fluorescent protein $(s G F P(S 65 T))$ gene driven by CaMV $35 \mathrm{~S}$ promoter. Scutellum calli at 3 weeks old were highly efficient for the regeneration of transformants. The transformation efficiencies ranged from 15 to $34 \%$ in seven leading varieties of nonglutinous rice. The presence of the foreign genes in the genome was confirmed by southern blot analysis, and the expression of $s G F P(S 65 T)$ gene was detected in several tissues of transformants with bright fluorescent signals under a fluorescent microscopy. The present study demonstrates the usefullness of $s G F P(S 65 T)$ gene as a reporter in transformed rice plants.
\end{abstract}

Agrobacterium-mediated transformation methods of Japonica rice have been reported in some cultivated varieties including Tsukinohikari, Koshihikari (Hiei et al., 1994), Nipponbare (Toki, 1997) and Yamahoushi (Yokoi et al., 1997). A Japonica rice cultivar, Koshihikari, is one of the most commercially cultivated varieties in Japan and is generally known to respond poorly to callus induction and to plantlet regeneration from calli in standard in vitro culture condition (Hiei et al., 1994, Yokoi et al., 1997). From a practical point of view, it is important to establish an efficient transformation method in leading rice cultivars including Koshihikari. The present study is focused on the leading varieties of rice in order to increase the efficiency of Agrobacterium - mediated gene transfer through improving culture media and conditions for callus induction and transformation.

Scutellum calli of rice have been shown to be superior for the efficient regeneration of transformed plants (Shimamoto et al., 1989, Hiei et al., 1994). Tsugawa and Otsuki (1993) have reported a remarkable callus growth in Koshihikari when cul- tured in a modified N6 medium, in which the ammonium nitrate had been removed from the N6 basal medium (Chu et al., 1975), the concentration of potassium nitrate had been decreased to $1 / 4$ of the original medium, and glutamine and aspartic acid had been added at a concentration of $1 \mathrm{~g} l^{-1}$ with supplements of $2 \mathrm{mg} l^{-1} 2,4-\mathrm{D}$ and $3 \%$ sucrose. In our preliminary experiment, the presence of glutamine and aspartic acid in a culture medium induced scutellum calli more effectively than that of proline and casamino acids. Thus the medium by Tsugawa and Otsuki (1993) was used as a basal medium in the present study. The media used for the callus culture and transformation are listed in Table 1.

Dehusked seeds of Koshihikari were sterilized with $70 \%$ ethanol for $30 \mathrm{sec}, 2.1 \% \mathrm{NaClO}$ for 15 min, and then rinsed 3 times with sterile water. To induce scutellum calli, the sterilized seeds were inoculated on KA1 medium and incubated at $30{ }^{\circ} \mathrm{C}$ under a day-length of $14 \mathrm{~h}$. We have compared the effects of carbohydrates on the induction and growth of the scutellum callus in Koshihikari. When 
$3 \%$ maltose was added to the medium as a substitute for sucrose, the largest number of scutellum calli (570 pieces) was induced from 54 seeds. We, therefore, employed 3\% maltose as a carbohydrate and here after referred to this medium as the KA1 medium (Table 1). Actively proliferating calli thus obtained were used for further transformation experiments.

Agrobacterium tumefaciens EHA101 (Hood et al., 1986) used for transformation has a binary vector, pIG121Hm harboring $\beta$-glucuronidase (GUS) gene and hygromycin resistance (HPT) gene (Fig. 1A, Ohta et al., 1990). The EHA101 strain was grown for 3 days at $28^{\circ} \mathrm{C}$ in dark on $\mathrm{AB}$ medium (Chilton et al., 1974) containing 50mg $l^{-1}$ hygromycin (Boehringer Mannheim). The grown bacteria were collected with a spoon and suspended in KA1 liquid medium containing $10 \mathrm{mg} l^{-1}$ acetosyringone (Aldrich). Scutellum calli were immersed in a bacterial suspension for $1.5 \mathrm{~min}$ and transferred onto the filter paper to remove excess liquid. The calli were incubated on $\mathrm{KA} 1$ - co medium and for 3 days at $28^{\circ} \mathrm{C}$ in the dark. After the co-cultivation, they were washed with sterile water and rinsed with KA1 liquid medium containing $250 \mathrm{mg} \mathrm{l}^{-1}$ carbenicillin (Wako Pure Chemicals) followed by incubation on KA1 - se medium for 3 weeks at $30{ }^{\circ} \mathrm{C}$ with a day-length of 14h. After subculturing on fresh KA1-se medium

Table 1. Culture media used for callus induction and plantlet regeneration

\begin{tabular}{|c|c|}
\hline KA1 & $\begin{array}{l}\text { Modified } \mathrm{N}^{\mathrm{a}} \text { basal salts containing } 1 / 4 \mathrm{KNO}_{3} \text { without } \mathrm{NH}_{4} \mathrm{NO}_{3}{ }^{\mathrm{b}}, \mathrm{MS}^{\mathrm{c}} \text { vitamins, } 2 \mathrm{mg} l^{-1} \\
2,4-\mathrm{D}, 30 \mathrm{~g} l^{-1} \text { maltose, } 1 \mathrm{~g} l^{-1} \text { aspartic acid, } 8 \mathrm{~g} l^{-1} \text { agarose }(\mathrm{pH} 5.8)\end{array}$ \\
\hline $\mathrm{KA} 1-\mathrm{co}$ & KA1 medium, $10 \mathrm{~g} l^{-1}$ glucose, $10 \mathrm{mg} l^{-1}$ acetosyringone (pH5.2) \\
\hline KA1-se & KA1 medium, 250 $\mathrm{mg} \mathrm{l}^{-1}$ carbenicillin, $50 \mathrm{mg} l^{-1}$ hygromycin (pH5.8) \\
\hline KA2 & $\begin{array}{l}\text { Modified } \mathrm{N}^{\mathrm{a}} \text { basal salts, } \mathrm{MS}^{\mathrm{c}} \text { vitamins, } 0.4 \mathrm{mg} l^{-1} 2,4-\mathrm{D}, 0.5 \mathrm{mg} l^{-1} \mathrm{ABA}, 0.1 \mathrm{mg} l^{-1} \\
\text { kinetin, } 30 \mathrm{~g} l^{-1} \text { maltose, } 30 \mathrm{~g} l^{-1} \text { sorbitol, } 2 \mathrm{~g} l^{-1} \text { casamino acids, } 1 \mathrm{~g} l^{-1} \text { glutamine, } 1 \mathrm{~g} l \\
{ }^{-1} \text { aspartic acid, } 125 \mathrm{mg} l^{-1} \text { carbenicillin, } 50 \mathrm{mg} l^{-1} \text { hygromycin, } 8 \mathrm{~g} l^{-1} \text { agarose (pH5.8) }\end{array}$ \\
\hline KA3 & $\begin{array}{l}\text { Modified } \mathrm{N}^{\mathrm{a}} \text { basal salts, } \mathrm{MS}^{\mathrm{c}} \text { vitamins, } 0.5 \mathrm{mg} l^{-1} \mathrm{BAP}, 0.2 \mathrm{mg} l^{-1} \mathrm{IAA}, 30 \mathrm{~g} l^{-1} \\
\text { maltose, } 30 \mathrm{~g} l^{-1} \text { sorbitol, } 2 \mathrm{~g} l^{-1} \text { casamino acids, } 1 \mathrm{~g} l^{-1} \text { glutamine, } 1 \mathrm{~g} l^{-1} \text { aspartic acid, } \\
125 \mathrm{mg} l^{-1} \text { carbenicillin, } 25 \mathrm{mg} l^{-1} \text { hygromycin, } 8 \mathrm{~g} l^{-1} \text { agarose (pH5.8) }\end{array}$ \\
\hline
\end{tabular}

2,4-D, 2,4-dichlorophenoxy acetic acid; ABA, abscisic acid; BAP, 6- benzyl-aminopurine; IAA, 3indole acetic acid. ${ }^{\mathrm{a}} \mathrm{N} 6$ from Chu et al. (1975); ${ }^{\mathrm{b}}$ Tsugawa and Otsuki (1993); ${ }^{\mathrm{c}}$ MS from Murashige and Skoog (1962).

A

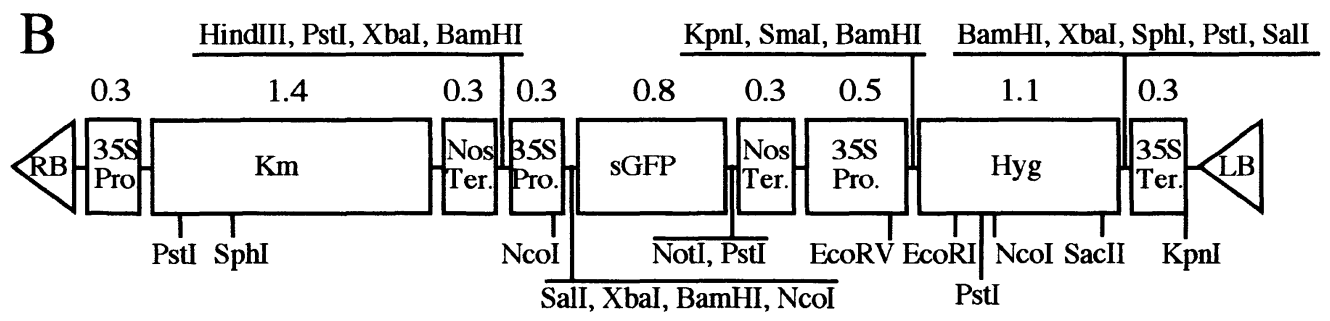

Fig. 1. Physical map of T-DNA region of the introduced genes.

(A) pIG121Hm and (B) pGFPKH. RB, right border; LB, left border; 35S Pro., cauliflower mosaic virus 35S promoter; Km, kanamycin resistance gene (NPTII); Nos Ter., nopaline synthase terminator; Intron-GUS, $\beta$ glucuronidase gene with intron; Hyg, hygromycin resistance gene (HPT); 35S Ter., cauliflower mosaic virus 35S terminator; sGFP, synthetic green fluorescence protein gene (S65T). The size (kbp) of each element and typical restriction endonuclease sites are indicated above and below the box, respectively. 
for several weeks, the actively growing calli were placed on KA2 medium for 1 week and finally transferred onto KA3 medium for regeneration. The regenerated plantlets were transferred to pots and grown in greenhouse.

The transformation efficiencies were compared using scutellum calli from different periods of culture (Table 2). High frequencies of hygromycinresistant calli (54 to 57\%) and transformed plants (25 to $34 \%$ ) were obtained from 19- and 27-dayold calli. When 34 -day-old calli were used, the transformation efficiency was drastically decreased with only $4 \%$ hygromycin-resistant calli and no regenerated plants. This confirms the importance of the culture period of calli for transformation, and suggests that the scutellum calli grown for approxi- mately 3 weeks are the best for an efficient transformation of rice.

In these experiments, more than three hundred putative transformants have been obtained using Koshihikari. Some of the transformants were analyzed by Southern blot hybridization to detect the integrated genes in their genomic DNA and to estimate the copy number of the transgene. Genomic DNAs were isolated from 15 hygromycin - resistant plants using the Nucleon Phytopure Plant DNA Extraction Kit (Amersham), followed by digestion with HindIII, a single site in the T-DNA region of the plasmid vector (Fig. 1A), and hybridized with GUS or HPT gene probes labeled with digoxygenin using DIG DNA Labeling Kit (Boehringer Mannheim). The transgene was proven to be

Table 2. Effects of the growth period of scutellum calli on the frequency of hygromycin- resistant transformants.

\begin{tabular}{cccc}
\hline \multirow{2}{*}{$\begin{array}{c}\text { Growth period of } \\
\text { scutellum calli (days) }\end{array}$} & $\begin{array}{c}\text { Number of calli } \\
\text { inoculated }^{\text {a }}\end{array}$ & \multicolumn{2}{c}{ Hygromycin resistant } \\
\cline { 3 - 4 } 19 & 100 & 57.0 & Calli(\%) \\
27 & 100 & 54.0 & Regenerated plants(\%) \\
\hline 34 & 100 & 4.0 & 25.0 \\
& & 4.0 & 0.0 \\
\hline
\end{tabular}

${ }^{a}$ The calli were co-cultured with Agrobacteriun tumefaciens harbouring $\mathrm{pIG} 121 \mathrm{Hm}$.

Table 3. Estimated copy number of the transgene in the transformants of Koshihikari

\begin{tabular}{|c|c|c|c|c|}
\hline \multirow[t]{2}{*}{ Transformant } & \multirow[t]{2}{*}{$H P T$ gene } & \multirow[t]{2}{*}{ GUS gene } & \multicolumn{2}{|c|}{$\begin{array}{c}\text { Number of } R_{1} \text { plants with } \\
\text { hygromycin }\end{array}$} \\
\hline & & & Resistance & Sensitive \\
\hline 1 & 6 & 6 & $\mathrm{nt}$ & $\mathrm{nt}$ \\
\hline 2 & 5 & 6 & $\mathrm{nt}$ & $\mathrm{nt}$ \\
\hline 3 & 1 & 1 & nt & $\mathrm{nt}$ \\
\hline 4 & 3 & 3 & 28 & 2 \\
\hline 5 & 1 & 1 & $\mathrm{nt}$ & nt \\
\hline 6 & 2 & 2 & 21 & 9 \\
\hline 7 & 1 & 1 & 23 & 7 \\
\hline 8 & 4 & 3 & $\mathrm{nt}$ & $\mathrm{nt}$ \\
\hline 9 & 2 & 2 & $\mathrm{nt}$ & $\mathrm{nt}$ \\
\hline 10 & 2 & 2 & 15 & 13 \\
\hline 11 & 5 & 5 & nt & $\mathrm{nt}$ \\
\hline 12 & 7 & 7 & $\mathrm{nt}$ & $\mathrm{nt}$ \\
\hline 13 & 4 & 4 & $\mathrm{nt}$ & $\mathrm{nt}$ \\
\hline 14 & 4 & 4 & 20 & 10 \\
\hline 15 & 2 & 1 & $\mathrm{nt}$ & $\mathrm{nt}$ \\
\hline Non- transformant -1 & 0 & 0 & 0 & 25 \\
\hline Non- transformant -2 & 0 & 0 & 0 & 25 \\
\hline
\end{tabular}

nt, not tested 
integrated in all the transformants examined (Table 3). The copy number of the transgene varied from one to seven in the transformants. In some of the plants, the numbers of $G U S$ and HPT genes integrated were not always the same, indicating that the $\mathrm{T}$-DNA regions might be rearranged during integration into the genomic DNA. The stable transmission of the transgene to the progeny was confirmed with $\mathbf{R}_{1}$ seeds germinated on agar medium containing $50 \mathrm{mg} \mathrm{l}^{-1}$ hygromycin (Table 3). The transformants, No.6 and 7, showed a segregation ratio of 3:1 as expected from the Mendelian inheritance of a single locus. The transformant No.4 showed the ratio of $15: 1$, indicating that the transgenes are located in the two loci. The other two transformants, No.10 and 14 showed a segregation ratio less than $3: 1$. In these plants, it would be possible that the transgenes were located on a single locus, but that some of the resistant offspring were counted as sensitive due to weak expression of the gene. These genetic analyses suggest that multiple copies of transgenes were integrated in to a single locus or a few loci on the genome of transformants.

We examined the expression of the GUS gene in 64 putative transformants and detected GUS activity in the roots of 59 plants, indicating that more than $90 \%$ of the transformants expressed the GUS gene. We also tested the usefulness of a synthetic green fluorescent protein $(s G F P(S 65 T))$ as reporter gene in transgenic rice plants. In the $\operatorname{sGFP}(\mathrm{S} 65 \mathrm{~T})$, the serine residue at position 65 was replaced with a threonine to enhance and stabilize fluorescent signal in the plant cells (Chiu et al., 1996). The amino acid replacement in the GFP has been reported to bring about a 100 -fold brighter fluorescent signal, swifter chromophore formation and slower photobleaching in plant cells, when compared with the original GFP from jellyfish (Chiu et al., 1996). We constructed a binary vector, pGFPKH containing $s G F P(S 65 T)$ gene and hygromycin - resistance (HPT) gene (Fig. 1B), and introduced into A. tumefaciens EHA101. By the same transformation method as described above, scutellum calli of Koshihikari were transformed, and 11 transformants were obtained. Expression of the $s G F P(S 65 T)$ gene was observed essentially as described by Chiu et al. (1996) under a fluorescence microscope (Olympus) with a filter set providing $490 \mathrm{~nm}$ excitation and $515 \mathrm{~nm}$ emission light. The sGFP expressions were clearly observed in the mature seeds, leaf blades and roots of the transformants (Fig. 2). In the leaf blades, however, intensity of green fluorescence was less than the other organs, due to the interference of autofluorescence derived from chlorophyll. The fluorescence intensity of the sGFP also varied among the individual transformants. Nagatani et al. (1997) have reported the transient expression of GFP in rice embryos following particle bombardment and the heat induced expression of the gene in roots of the transformant. The present result demonstrates the expression of the stably introduced $s G F P(S 65 T)$ gene in various tissues of the transformed rice plants, suggesting the usefulness of $s G F P(S 65 T)$ as a reporter gene for monitoring of gene expression in the whole rice plant.

To investigate the applicability of this transformation method to other rice cultivars, we examined seven nonglutinous rice cultivars, Natsuhikari, Akitakomachi, Kinuhikari, Dontokoi, Yamahikari and Yamadanishiki, and a glutinous rice cultivar, Ayumimochi. All of these cultivars are commercially cultivated in central regions of Japan. The frequencies of callus induction from scutellum and of hygromycin - resistant transformants in the nonglutinous cultivars were as high as that in Koshihikari (Table 4). However, the glutinous rice, Ayumi-

Table 4. Frequencies of scutellum calli and hygromycin-resistant transformants regenerated from the calli in several leading varieties of Japonica rice.

\begin{tabular}{lccccc}
\hline \multirow{2}{*}{ Cultivars } & \multirow{2}{*}{$\begin{array}{c}\text { Seeds } \\
\text { inoculated }\end{array}$} & \multirow{2}{*}{$\begin{array}{c}\text { Callus-induced } \\
\text { seeds(\%) }\end{array}$} & \multirow{2}{*}{$\begin{array}{c}\text { Number of calli } \\
\text { infected }\end{array}$} & \multicolumn{2}{c}{ Hygromycin resistant } \\
\cline { 5 - 6 } & & & & Calli(\%) & Transformants(\%) \\
\hline Koshihikari & 32 & 68.8 & 298 & 54.0 & 24.0 \\
Natsuhikari & 32 & 71.9 & 288 & 19.0 & 16.0 \\
Akitakomachi & 32 & 68.8 & 400 & 24.0 & 17.3 \\
Kinuhikari & 32 & 65.6 & 388 & 18.0 & 15.0 \\
Dontokoi & 32 & 50.0 & 296 & 24.0 & 20.0 \\
Yamahikari & 32 & 68.8 & 419 & 36.0 & 25.0 \\
Yamadanishiki & 32 & 18.8 & 100 & 54.0 & 24.0 \\
Ayumimochi & 32 & 34.4 & 171 & 6.0 & 5.0 \\
\hline
\end{tabular}



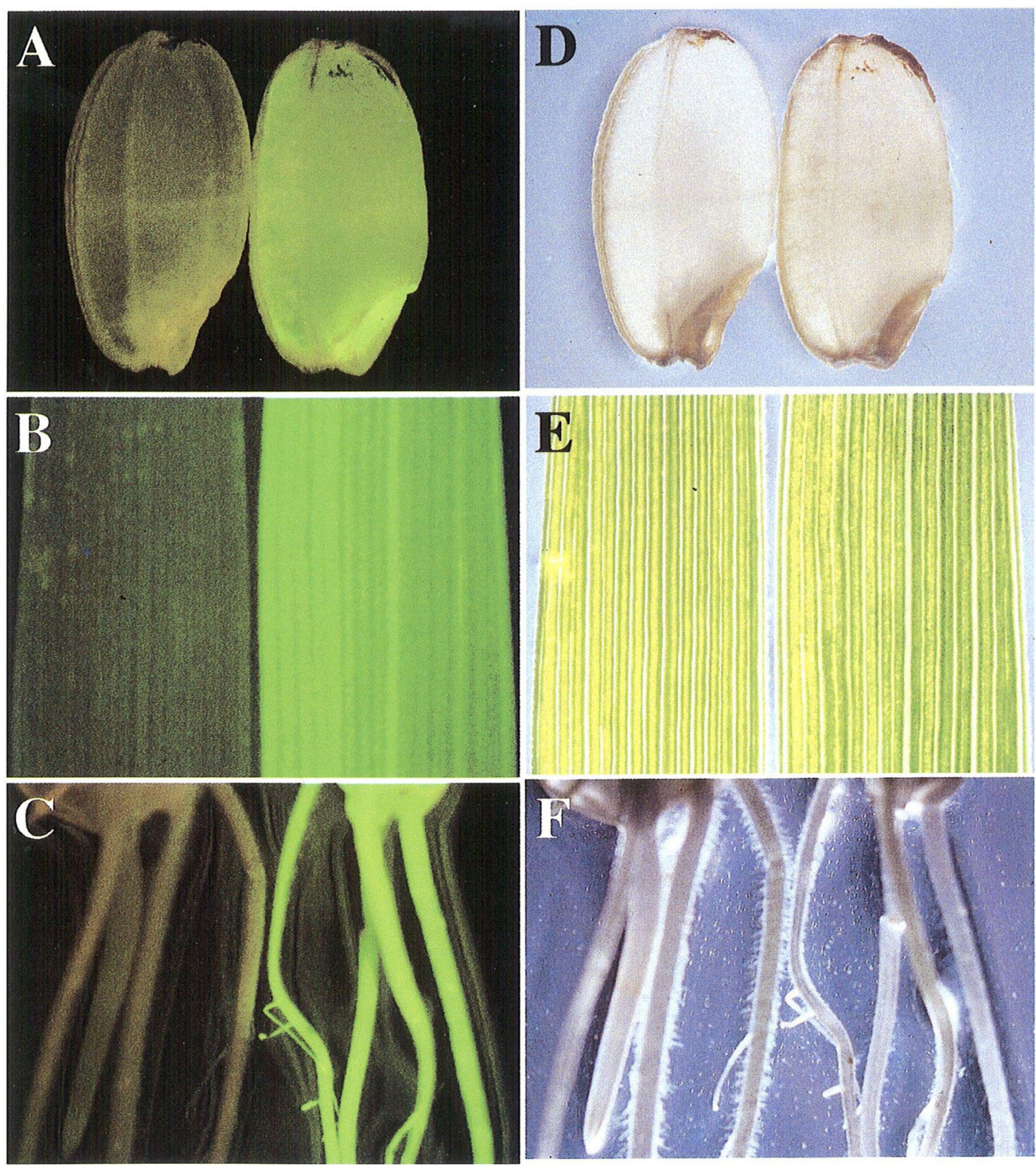

Fig. 2 Experssion of the sGFP(S65T) gene in some tissues of transformants.

Expression of sGFP(S65T) gene in seed (A), leaf blade (B) and root (C) observed under the fluorescence microscopy, and bright-field microscopy (D, E and F, respectively). Each panel contains tissues from transformant (right) and non-transformant (left). 
mochi showed a significantly lower frequency of transformation. This might be due to the different genetic background of Ayumimochi. Successful transformations using Agrobacterium have been reported in Japonica rice cultivars by Hiei et al. (1994) and Yokoi et al. (1997), in Indica rice by Rashid et al. (1996) and Aldemita and Hodges (1996), and in Javanica rice by Dong et al. (1996). Their transformation frequencies ranged from approximately 15 to $34 \%$, which are comparable to those obtained in our present experiments. Hiei et al. (1994) used a superbinary vector to obtain a high transformation frequency in rice cultivars. In the present study, however, we obtained high transformation frequencies even when using conventional binary vector derived from pBIN19. Therefore, the Agrobacterium -mediated transformation method described here provides a wide application to the molecular breeding of Japonica rice including Koshihikari and its related cultivars.

\section{Acknowledgement}

The authors wish to thank Dr. K. Nakamura for his kind gift of plasmid vector, pIG121Hm, and Dr. E. Hood for his gift of Agrobacterium tumefaciens EHA101. We would also like to thank Dr. Y. Tabei and Mr. H. Tsugawa for their technical advice.

\section{References}

Aldemita, R., Hodges, T., 1996. Agrobacterium tumefaciens-mediated transformation of Japonica and Indica rice varieties. Planta, 199: 312- 617.

Chilton, M. - D., Currier, T., Farrand, S., Bendich, A., Gordon, M., Nester, E., 1974. Agrobacterium tumefaciens DNA and PS8 bacteriophage DNA not detected in crown gall tumors. Proc. Natl. Acad. Sci., USA, 71: $3672-3676$.

Chiu, W.- L., Niwa, Y., Zeng, W., Hirano, T., Kobayashi, H., Sheen, J., 1996. Engineered GFP as a vital reporter in plants. Curr. Biol., 6: 325-330.

Chu, C.-C., Wang, C.- C., Sun, C.-S., Hsu, C., Yin, K.-C., Chu, C. -Y., Bi, F. - Y., 1975. Establishment of an efficient medium for anther culture of rice through comparative experiments on the nitrogen sources. Scientia Sinica, 18: $659-668$.

Dong, J., Teng, W., Nuchholz, W.G., Hall, T.C., 1996. Agrobacterium-mediated transformation of Javanica rice. Mol. Breed., 2: 267-276.

Hiei, Y., Ohta, S., Komari, T., Kumashiro, T., 1994. Efficient transformation of rice (Oryza sativa, L.) mediated by Agrobacterium and sequence analysis of the boundaries of the T-DNA. Plant J., 6: 271-282.

Hiei, Y., Komari, T., Kubo, T., 1997. Transformation of rice mediated by Agrobacterium tumefaciens. Plant Mol. Biol., 35: 205-218.

Hood, E., Helmer, G., Fraley, R., Chilton, M.-D., 1986. The hypervirulence of Agrobacterium tumefaciens A281 is encoded in a region of pTiBo542 outside of T-DNA. J. Bacteriol., 168: 1291 - 1301.

Murashige, T., Skoog, F., 1962. A revised medium for rapid growth and bio assays with tobacco tissue culture. Physiol. Plant., 15: 473- 497.

Nagatani, N., Takumi, S., Tomiyama, M., Shimada, T., Tamiya, E., 1997. Semi-real time imaging of the expression of maize polyubiquitin promoter-GFP gene in transgenic rice. Plant Sci., 124: 49-56.

Ohta, S., Mita, S., Hattori, T., Nakamura, K., 1990. Construction and expression in tobacco of a $\beta$-glucuronidase (GUS) reporter gene containing and intron within the coding sequence. Plant Cell Physiol., 31: 805-813.

Rashid, H., Yokoi, S., Toriyama, K., Hinata, K., 1996. Transgenic plant production mediated by Agrobacterium in Indica rice. Plant Cell Rep., 15: 727-730.

Shimamoto, K., Terada, R., Izawa, T., Fujimoto, H., 1989. Fertile transgenic rice plants regenerated from transformed protoplasts. Nature, 338: 274- 276.

Toki, S., 1997. Rapid and efficient Agrobacterium - mediated transformation in rice. Plant Mol. Biol. Rep., 15: 1621.

Tsugawa, H., Otsuki, Y. 1993. Wide application of cell culture system of rice. I. Koshihikari. Jpn. J. Breed., 43 (suppl. 2): 121. (in Japanese).

Yokoi, S., Tsuchiya, T., Toriyama, K., Hinata, K., 1997. Tapetum - specific expression of the Osg6B promoter$\beta$-glucuronidase gene in transgenic rice. Plant Cell Rep., 16: 363-367. 